OLIVEIRA, J.R. et al. Biossegurança e vazio sanitário das instalações zootécnicas. PUBVET, Londrina, V. 4, N. 7, Ed. 112, Art. 754, 2010.



PUBVET, Publicações em Medicina Veterinária e Zootecnia.

\title{
Biossegurança e vazio sanitário das instalações zootécnicas
}

Josimar Rodrigues Oliveira (1); Érica Alves Marques (2); Isaac Alves Tonaco (2); Neimar de Freitas Duarte (3).

(1) Graduando em Engenharia Agronômica e bolsista do CNPq do Instituto Federal de Educação, Ciência e Tecnologia de Minas Gerais - Campus Bambuí (IFMG - Campus Bambuí); (2) Graduando em Engenharia Agronômica - IFMG - Campus Bambuí (3) Professor do IFMG - Campus Bambuí.

\section{Resumo}

O Brasil é um dos países que mais se desenvolveu nestes últimos anos no setor pecuário, devido a alta demanda, principalmente de consumidores estrangeiros. O Objetivo deste trabalho é apresentar a comunidade acadêmica e profissionais da área, a importância da limpeza e desinfecção das instalações zootécnicas utilizadas para a criação intensiva de animais, são técnicas simples de serem realizadas, podendo até mesmo serem implantadas como um programa nas diversas criações animais, melhorando consequentemente a saúde animal, aumentando o desempenho e a produção de carne, leite, ovos ou matéria prima de qualidade para as indústrias processadoras.

Palavras- Chave: limpeza, sanidade animal, desenvolvimento. 
OLIVEIRA, J.R. et al. Biossegurança e vazio sanitário das instalações zootécnicas. PUBVET, Londrina, V. 4, N. 7, Ed. 112, Art. 754, 2010.

\title{
Biosecurity and disinfection of the installations zootechnics
}

\begin{abstract}
The Brazil is a country wath more if developed us last years in cattle-raising, just of high demand, principally of the consumers foreign. The objective of present work is to introduce of the community academic and professionals of the area, the importance of the clean and disinfection of the zootechnics installations using for intensive creation animals, are technically simples of to lifted executed, improved the animal health, hight discharge and production of the meat, milk, eggs or prime matter of the quality about processing industries.
\end{abstract}

Keywords: clean, animal sanity, development.

\section{INTRODUÇÃO}

A pecuária brasileira é um dos ramos que se destacam dentro do cenário nacional, devido a grande demanda tanto dos consumidores, quanto para as indústrias do setor que diariamente criam novos produtos derivados da matéria prima animal, aumentando a procura por matéria prima e impondo certa pressão para o aumento da produtividade.

Lopes e Daher (2009) apresentam dados em que a produção de carne bovina, de frango e suína tem sido crescente desde 1990, alcançando em 2007 uma produção de 10,$6 ; 9,8$ e 3 milhões de toneladas.

Atualmente são vários os produtos processados que são comercializados no Brasil em grande escala, como por exemplo, o leite UHT, leite pasteurizado, massas de sêmola com ovos, ovo em pó (criado em 2008 e já é um sucesso em vários estados), cortes embalados, cortes congelados, feijoada em lata, produção de salsichas, linguiças, empanados, bifes de hambúrguer, produção de roupas de lã, casacos e jaquetas de couro, botas de couro, selas, entre outras. 
OLIVEIRA, J.R. et al. Biossegurança e vazio sanitário das instalações zootécnicas. PUBVET, Londrina, V. 4, N. 7, Ed. 112, Art. 754, 2010.

Portanto para que os produtores consigam suprir tais demandas do mercado é necessário que este possa utilizar adequadamente as tecnologias de produção disponíveis. De acordo com Zardo e Lima (1999), o desenvolvimento genético de animais mais produtivos e mais exigentes em ambiente, nutrição e manejo, traz a necessidade de se buscar um maior profissionalismo na atividade, adotando-se tecnologias e procedimentos que maximizem o seu desempenho ao menor custo de produção possível.

Para que se tenha um ótimo desempenho do animal, atingindo grandes produtividades, vários parâmetros zootécnicos devem andar aliados. Tudo começa na escolha do animal, observando-se suas características genéticas, fenotípicas, conversão alimentar e sanidade. Com isso são necessários conciliar outros fatores de grande importância como, por exemplo, nutrição balanceada e adequada, controle de zoonoses, bioclimatologia e ambiência para aumentar o bem estar animal, manejo racional e com profissionais qualificados, além do manejo de limpeza, desinfecção e vazio sanitário das instalações.

Devido a isto, o objetivo deste trabalho é levar a comunidade acadêmica, produtores e profissionais da área a importância e como realizar de forma correta a limpeza, desinfecção e o vazio sanitário das instalações zootécnicas, que muitas das vezes é realizada de maneira errada, devido a uma falta de orientação aos produtores, que às vezes realizam somente uma limpeza simples nas instalações.

\section{Biossegurança animal}

Após alguns acontecimentos marcantes do setor pecuário como a doença da vaca louca, gripe aviária e outras que ocasionaram drasticamente uma queda na comercialização de produtos de origem animal durante certo período, ocasionando até mesmo um início de crise no setor, tem se falado muito em biossegurança animal.

A Biossegurança envolve justamente os aspectos de sanidade animal, dentro deste contexto pode se destacar a limpeza, desinfecção e o vazio sanitário, porém a biossegurança animal não gira somente em torno destes 
OLIVEIRA, J.R. et al. Biossegurança e vazio sanitário das instalações zootécnicas. PUBVET, Londrina, V. 4, N. 7, Ed. 112, Art. 754, 2010.

três itens, outros fatores como qualidade dos alimentos (livres de patógenos), qualidade da água (livre de coliformes ou microrganismos patógenos), manejo dos dejetos, controle de roedores e insetos nas instalações de criação animal ou mesmo em depósitos e o uso de antibióticos também devem ser levados em consideração.

Este conjunto de programas e medidas visam diminuir, de maneira significativa, a inevitável exposição dos animais a agentes infecciosos e predadores naturais. Estabelece um nível de segurança para os seres vivos diminuindo o risco de ocorrência de enfermidades agudas ou crônicas em uma determinada população (SANTOS, 1999; SESTI, 1999).

\section{Importância da Limpeza, Desinfecção e vazio sanitário das Instalações}

O processo de limpeza consiste na remoção dos detritos acumulados nas instalações, com o objetivo de reduzir a carga microbiana e minimizar o contato dos animais com excesso de matéria orgânica, a qual potencialmente aumenta o risco da veiculação de agentes patogênicos aos animais (SESTI, 1998).

A desinfecção é o conjunto de medidas empregadas para impedir a penetração e crescimento de germes num determinado ambiente ou estrutura, tornando-os livres de agentes infectantes, com o uso de substâncias desinfetantes ou outras formas físicas de desinfecção (SPINOSA, 1997).

Por fim, considera-se vazio sanitário o período em que a instalação permanece vazia e os processos de limpeza e desinfecção são realizados.

O vazio sanitário permite a destruição de certos organismos não atingidos pela desinfecção, mas que se tornam sensíveis à ação dos agentes físicos naturais como: aumento da temperatura, ventilação e incidência de sol, permitindo a secagem das instalações. O tempo de vazio sanitário varia com o tipo de criação, status sanitário da propriedade e a programação dos novos lotes.

Os procedimentos de limpeza e desinfecção fazem parte de uma das etapas mais importantes dentro do ciclo de produção, estando presente em 
OLIVEIRA, J.R. et al. Biossegurança e vazio sanitário das instalações zootécnicas. PUBVET, Londrina, V. 4, N. 7, Ed. 112, Art. 754, 2010.

todas as fases de criação. De acordo com Gordon e Morishita (2002), a limpeza e desinfecção quando realizadas de maneira eficiente são pontos cruciais para uma boa sanidade, devendo ser adotados como um programa de biosseguridade. Quando realizada em final de ciclo de maneira correta, controla os possíveis problemas e promovem um sucesso na produção (SALDIVAR, 2001).

Para se adotar um programa de limpeza e desinfecção eficientes são necessários à utilização de produtos de comprovada eficácia, adequando às características próprias de cada instalação e equipamentos, mão-de-obra qualificada e treinada, conhecedora da necessidade de uma perfeita atuação nestas atividades e o conhecimento dos agentes etiológicos instalados na propriedade.

A realização rotineira de um processo de higienização detalhado é a condição indispensável para a manutenção de um alto nível de saúde dos animais, pois, através da redução da carga microbiana nas instalações, equipamentos e conseqüentemente no ambiente do sistema de produção, seguramente se reduzirá o risco de ocorrência de doenças bem como será possível o controle ou a erradicação de enfermidades presentes.

\section{Manejo das Instalações na avicultura e suinocultura}

Apesar de já estar bem definida a importância da limpeza e da desinfecção para garantir uma suinocultura e avicultura eficiente e lucrativa, muitos técnicos não recomendam ou não adotam com o rigor necessário.

Os conhecimentos atuais demonstram que as dependências que abrigam aves e suínos, são locais de intensa multiplicação de agentes infecciosos, com o que se rompe o equilíbrio existente entre os animais e os microorganismos de seu meio ambiente.

Segundo Berchieri e Macari (2000), doenças como Coriza infecciosa, Botulismo, Doença de Gumboro, Doença de Newcastle, Marek, Candidíase, Coccidiose e outras, podem atacar severamente áreas com criações avícolas 
OLIVEIRA, J.R. et al. Biossegurança e vazio sanitário das instalações zootécnicas. PUBVET, Londrina, V. 4, N. 7, Ed. 112, Art. 754, 2010.

em que foram realizados limpeza e desinfecção de forma inadequada, ou não foram realizadas.

Sobestiansky et al. (1999) frisa que no caso da suinocultura podem surgir doenças como Circovirose, Disinteria suína, Rinite atrófica, Artrites, Coccidiose, Helmintose, Parvovirose suína e outras.

\section{Limpeza das instalações na suinocultura}

O processo mais utilizado para manter a biosseguridade das instalações segue os conceitos metodológicos indicados por Sesti (1998).

Inicia a limpeza seca, com pá e vassoura, imediatamente após a retirada dos animais. Esvazia as calhas ou fossas existentes, desmontando e lavando todos os equipamentos da sala.

Após este procedimento inicia-se a limpeza úmida, no máximo 3 horas após a saída dos animais, umedecendo previamente a instalação com água contendo um detergente para facilitar a remoção de toda a matéria orgânica aderida nas paredes e pisos, é recomendado fazer a limpeza úmida com lava jato de alta pressão (1000 a 2000 libras).

\section{Desinfecção e vazio sanitário das instalações para suínos}

No dia seguinte ao da lavagem, aplica-se o desinfetante, com a instalação totalmente seca, usando cerca de $400 \mathrm{~mL}$ da solução/m² de superfície, observando com cuidado a correta diluição do desinfetante, seguindo sempre a recomendação do fabricante.

Deve-se desinfetar todas as superfícies da sala e todos os equipamentos. Nos meses de inverno, usar água pré aquecida a $37^{\circ} \mathrm{C}$ para diluir o desinfetante. Opcionalmente pode ser feita uma segunda desinfecção utilizando-se pulverização ou nebulização, cerca de duas horas antes do alojamento do próximo lote de animais, no caso de sala de maternidade, fazer essa segunda desinfecção com vassoura de fogo (lança chamas).

Como medida auxiliar no controle da coccidiose, aguardar vazio sanitário mínimo de 5 dias, deixando nesse período a sala fechada, após todo estes 
OLIVEIRA, J.R. et al. Biossegurança e vazio sanitário das instalações zootécnicas. PUBVET, Londrina, V. 4, N. 7, Ed. 112, Art. 754, 2010.

procedimentos pode-se montar os equipamentos e alojar os animais na sala limpa e desinfetada.

Este sistema de manejo de limpeza e desinfecção na suinocultura é comumente conhecido como "Todos dentro, todos fora". Conforme Fávero (2003), nas fases de cobrição e gestação, normalmente utiliza-se o sistema contínuo, sem realização de vazio sanitário.

Por esta razão, para reduzir a contaminação do ambiente, deve-se lavar e desinfetar as baias ou boxes sempre que um lote de fêmeas for retirado, sendo que a limpeza seca, com pá e vassoura na presença dos animais, deve ser feita diariamente de 1 a 3 vezes ao dia, dependendo do tipo de instalação.

\section{Limpeza das instalações na avicultura}

Segundo Ferreira (2008), deve-se realizar a limpeza e desinfecção na avicultura da seguinte maneira: a primeira etapa consiste na remoção do esterco aviário ou cama de frango de forma rápida, com a retirada do mesmo para longe das instalações.

Deve-se realizar a varredura do piso removendo a parte mais fina do esterco do piso, pois isto otimiza o uso da água e evita a formação de "lama" no piso, que pode interferir na eficiência do processo.

A lavagem do piso e dos equipamentos deve ser realizada utilizando-se água sob pressão.

\section{Desinfecção e vazio sanitário das instalações para aves}

Após este processo é realizada a desinfecção, sendo que a escolha do tipo de desinfetante a ser utilizado é importante para que se tenha eficiência, são vários os tipos e suas respectivas propriedades como mostra o Quadro 1.

Podem ser utilizados produtos ácidos que são eficazes contra grande parte dos microorganismos, álcoois, aldeídos, álcalis, compostos clorados, agentes oxidantes, compostos fenólicos, compostos de quaternário de amônio, entre outros, de acordo com as necessidades de cada região. 
OLIVEIRA, J.R. et al. Biossegurança e vazio sanitário das instalações zootécnicas. PUBVET, Londrina, V. 4, N. 7, Ed. 112, Art. 754, 2010.

\section{Quadro 1 - Propriedades dos principais desinfetantes utilizados em instalações zootécnicas.}

\begin{tabular}{|l|c|c|c|c|c|c|c|}
\hline \multicolumn{7}{|c|}{ DESINFETANTES } \\
\hline \multicolumn{1}{|c|}{ PROPRIEDADES } & $\begin{array}{c}\text { GLUTA- } \\
\text { RALDEIDO }\end{array}$ & $\begin{array}{c}\text { CLORHE- } \\
\text { XIDINA }\end{array}$ & CLORO & IODO & FENOL & $\begin{array}{c}\text { AMÔNIA } \\
\text { QUATER- } \\
\text { NÁRIA }\end{array}$ & FORMOL \\
\hline Bactericida & + & + & + & + & + & + & + \\
\hline Fungicida & + & - & - & + & + & \pm & + \\
\hline Viricida & + & + & \pm & + & + & \pm & + \\
\hline Toxicidade & + & - & + & - & + & - & + \\
\hline Faixa de pH efetivo & alcalino & alcalino & ácido & ácido & neutro & alcalino & alcalino \\
\hline $\begin{array}{l}\text { Ação na presença matéria } \\
\text { orgânica }\end{array}$ & +++ & + & + & +++ & ++++ & ++ & ++++ \\
\hline & & & & & & & \\
\hline $\begin{array}{l}\text { Equipamentos } \\
\text { incubatório }\end{array}$ & + & + & + & + & + & + & \pm \\
\hline Desinfecção da água & - & + & + & + & - & + & - \\
\hline Pessoas & - & + & + & + & - & + & - \\
\hline Lavagem de ovos & - & + & + & - & - & + & + \\
\hline Pisos & + & \pm & - & - & + & + & + \\
\hline Pedilúvio & + & - & - & - & + & + & - \\
\hline Habitações & + & - & \pm & + & \pm & + & + \\
\hline
\end{tabular}

+ : Atividade do desinfetante

- : Ausência de atividade

\pm : Atividade limitada a condições especiais

Fonte: Código Zoosanitário Internacional -O.I.E. - 5a. ed., 1986.

É recomendável que se realize um rodízio dos desinfetantes utilizados para diminuir a probabilidade do surgimento de uma possível resistência microbiana.

Após a higienização deve-se deixar o aviário fechado durante um período mínimo de 10 dias e antes do recebimento de novos animais deve ser feita uma nova desinfecção, no caso da Avicultura de Postura recomenda-se ainda, a retirada periódica do esterco e do chorume do aviário.

\section{Biossegurança na Bovinocultura}

No caso da bovinocultura, não há um vazio sanitário das instalações devido o sistema de criação ser intensivo. Porém, as instalações onde circulam os animais, as camas e a sala de ordenha devem ser mantidas limpas, 
OLIVEIRA, J.R. et al. Biossegurança e vazio sanitário das instalações zootécnicas. PUBVET, Londrina, V. 4, N. 7, Ed. 112, Art. 754, 2010.

evitando-se o acúmulo de terra e esterco, devem ser secadas e sempre conservadas em condições adequadas de uso.

Esses ambientes devem ser desinfetados quinzenalmente com soluções de cresóis ou fenóis a $1 \%$, iodofórmio a $0,05 \%$ ou com cal queimada.

A ordenhadeira deve ser lavada diariamente com água quente $\left(60^{\circ} \mathrm{C}\right)$ e detergente alcalino, e semanalmente com detergente ácido, deve-se realizar a limpeza mensal da válvula reguladora e anualmente uma limpeza geral da bomba de vácuo e mangueiras que tem contato direto com o leite.

\section{CONCLUSÃO}

Pode-se observar que a limpeza, desinfecção e o vazio sanitário são técnicas de manejo fáceis e simples de serem realizadas, podendo até mesmo serem implantadas como um programa de biossegurança nas diversas criações animais, melhorando consequentemente a saúde animal e aumentando o desempenho e a produção de carne, leite, ovos ou matéria prima de qualidade para as indústrias processadoras.

\section{REFERÊNCIAS}

BERCHIERI, J.A., MACARI, M. Doenças das aves. FACTA, Campinas, São Paulo, 490 p. 2000.

FÁVERO, J.A. (Coord.). Produção Suínos: Limpeza e Desinfecção. Sistemas de Produção, EMBRAPA Aves e Suínos, Concórdia, SC, v.2, Jan. 2003.

FERREIRA, H.C. O Desafio da Limpeza e desinfecção de galpões na avicultura. In: Conferência APINCO 2008 de Ciência e Tecnologia Avícolas, Anais... p.199-203, 2008.

GORDON, J.C.; MORISHITA, T.Y. Cleaning and Disinfection of Poultry Facilities. Veterinary Preventive Medicine, Ohio State University Fact Sheet, Columbus, 2002.

LOPES, A.S.; DAHER, E. Agronegócio e Recursos naturais no Cerrado: Desafios para uma coexistência harmônica. Lavras, MG, UFLA/ANDA, 2009.

SALDIVAR, R. J. Do we really know how to clean and disinfect animal facilities?. Texas A\&M University, Texas, EUA, 2001.

SANTOS, C.H.C. Biossegurança. In III Encontro Internacional de Ciências Aviárias de Uberlândia. Anais... Universidade Federal de Uberlândia, Uberlândia MG, p.63-76, 1999.

SESTI, L.A.C., SOBESTIANSKY, J., BARCELLOS, D. Limpeza e Desinfecção em Suinocultura. Suinocultura Dinâmica. Embrapa, ano VI, n.20, 1998. 
OLIVEIRA, J.R. et al. Biossegurança e vazio sanitário das instalações zootécnicas. PUBVET, Londrina, V. 4, N. 7, Ed. 112, Art. 754, 2010.

SESTI, L.A.C. Programas de Biosseguridade na Produção de Aves e Suínos: Filosofia, Similaridades e Diferenças. In: II Simpósio de Nutrição e Manejo de Aves e Suínos do Triângulo. Anais... Universidade Federal de Uberlândia, Uberlândia, p.15-30 1999.

SOBESTIANSKY, J. BARCELLOS, D., MORES, N., CARVALHO, L.F., OLIVEIRA, S. Clínica e Patologia Suína. Goiânia, Goiás, 464p. 1999.

SPINOSA, H., GORNIAK, S., BERNARDI, M. Farmacologia Aplicada a Medicina Veterinária. Guanabara, 1 ed, 1997, 545p.

ZARDO, A.O.; LIMA, G.J.M.M. Bipers: Alimentos para suínos. Boletim Informativo de Pesquisa e Extensão. EMBRAPA Suínos e Aves/EMATER-RS, Ano 8, n 12, Dez. 1999. 